\title{
Motivation of Athletes in Athletics at the Different Stages of the Sports Career
}

\author{
Rogaleva LIUDMILA ${ }^{1, \star}$, Kim ALLA $^{2}$ and Khon NATALYA ${ }^{3}$ \\ ${ }^{1}$ The Ural Federal University, Ekaterinburg, Russian Federation \\ ${ }^{2}$ Al-Farabi Kazakh National University, Almaty, Kazakhstan \\ ${ }^{3}$ Turan University, Almaty, Kazakhstan \\ ${ }^{*}$ Corresponding author
}

Keywords: Motivation, Athletes, Sports Career.

\begin{abstract}
Sports career is a long-term process, during which there are significant changes in the motivation of athletes. At the same time, despite the lack of unified motivation theory, it is practically important to know peculiarities of athletes' motivation with regard to specific kind of sports and the stages of the sports career. Motivation is a factor on which the effectiveness of sports activities and the level of achievements of athletes depend. The aim of the research was to study the leading motives of athletes at different stages of sports career. The study involved three groups, 55 people in total - 25 sportsmen of the initial stage of sportsmanship, 11 sportsmen engaged in the stage of sports perfection, and 10 professional athletes. The study used a standardized questionnaire to study the motivation of sports activities, which included 34 statements on personal and social motivation, as well as a standardized interview. The data proving differences in the motivation within the groups, as well as motives contributing to the development of long-term motivation leading in the context of achieving high sports skills are obtained.
\end{abstract}

\section{Introduction}

A sports career can be defined as a long-term sports activity aimed at high sports achievements and associated with the constant self-improvement of a person in one or several kinds of sports [1].

To features of sports career in such kind of sports as athletics, it is possible to attribute:

- The length of the sports career, which can last up to 35 years;

- Specific conditions of the competition depending on the season (winter and summer);

- A relatively later period of entering the professional level than in other sports;

- Mostly individual character of performance in competitions.

In connection with the duration of the sports career, one of the most topical problems is keeping motivation throughout its entire length.

The literature review reveals the absence of unified motivation theory relating motivation for sports activity. Among the scope of motivation theories the most popular are as follows: achievement goal theories [2], Deci and Ryan's self-determination theory [3], Maslow's selfrealization theory [4], and Weiner's attribution theory [5].

The practice of sports requires knowledge of motivation of athletes depending on the kind of sports and stages of the sports career.

This is due to the fact that motivation is not only a pivotal characteristic of the athlete's personality, but also a factor on which the effectiveness of sports activity and the level of achievements of athletes depends [6].

Our research goal was to study the leading motives in athletics activity at different stages of sports career.

\section{Research Methodology and Procedure}

The study was conducted on the basis of athletics club "The Ray" in Yekaterinburg, Russia. A total of 55 persons participated in the study. The first group - the sportsmen at the initial stage of 
sportsmanship, consisted of 25 persons, 14 years old in average, from the 1st youth to the first adult category in level of sportsmanship, winners of the regional championships, and prize-winners of the Russian competition. The second group was a group of sports perfection, consisted of 11 athletes, candidates for Master of sports and Masters of sports, with experience in athletics from 7 to 12 years, 21 years old in average. The third group consisted of 10 professional athletes, 26.5 years old in average, possessing the title of Honored Masters of sports, Masters of sports of international class, participants and prize-winners of the Olympic Games and world champions.

In the course of the motivation study, the first and second group of athletes filled in a modified standardized questionnaire for studying the motivation of sports activities, including 34 statements on personal and social motivation, developed by Dieter Teipel and Reinhild Kemper [7].

During the survey, athletes were to assess the importance of a statement from one to sex points. Each statement began with the statement 'I am athletics because ...', followed by the various answers such as, 'because I would like to be in the spotlight', 'I would like to earn good money in the sport', 'I like the attention of the public', 'I would like to achieve my goal (important and meaningful for me)' and others. The processing of the results was carried out by calculating the maximum score (6 points) obtained for each answer, which allowed us to rank the motive from the most significant to the most insignificant one. For professional athletes, questions were developed in the form of a standardized interview. The questions in the questionnaire for professionals were as follows: 'What were your main, determining motives for coming to the sports? What goals did you initially set yourself? Have you ever thought about ending your sports career?'

In particular, it was interesting to prove the idea if trauma, lesion or high sports success could motivate sports activity [8]. It was assumed that the standardized interview results of athletes' highest level of sportsmanship would help to better understand the leading motives of athletes at different stages of sports career.

\section{Results and Discussion}

In the course of the study it was revealed that the athletes of the group of initial sportsmanship demonstrated poorly differentiated motives, their motivational sphere was unstable, as a result motivation for sports activity changed rather quickly under the influence of both external and internal factors.

At the same time, it is possible to note the motives more preferable among the majority of athletes in the group of initial sportsmanship:

1. I want to show high results $-80 \%$

2. Athletics is important for strengthening and development the will and character $-72 \%$

3. Training in athletics gives me joy $-64 \%$

4. I like to feel like the leader of the team, or group - 58\%

5. I would like to check what I am able to achieve, what I am competent for - $56 \%$.

Based on the responses of athletes in the initial sportsmanship team, it can be concluded that the main motives at the beginning of a sports career in athletics are: aspiration to achieve, developing their abilities, experiencing joy from playing sports as well as self-affirmation and self-development.

Thus, the results obtained are more in line with Deci and Ryan's self-determination theory (competence and autonomy) as well as achievement theory (achieving the goal). It is interesting to note that meaningful attitude (E. Deci) as a social factor is not among the leading motives for $60 \%$ of participants, which is possible to explain by the fact that athletics is an individual kind of sports focused on personal achievements and individual motives, displacing social motivation.

The second study conducted in the group of sports improvement revealed the existence of the hierarchy of motives among the majority of athletes in terms of their significance. The motivation of athletes at this stage is characterized by an awareness of what they are striving for and why it matters to them. It should be noted that their answers indicate a reassessment of the role of sport in their lives.

Among the most significant personal and social motives for athletics in the group of sports excellence were the following answers: 
1. The desire to achieve high results - $100 \%$

2. The desire for self-fulfillment $-90 \%$

3. The desire for self-realization - $90 \%$

4. I like particularly this kind of sports $-75 \%$

5. Performance of tasks set by the coach $-70 \%$.

6. Good relationship in the team between the athletes $-70 \%$

According to the results of our research, it can be said that extension and development of a sports career are correlated with the formation of motives for achieving significant goals, high sports results and strengthening the interest for the sports chosen as well as the desire for self-realization. Among the most significant motives, a social motive - good relations in a team, takes place.

The results obtained allow us to conclude that entering a higher level of sportsmanship by the athletes reveals the motives for the goal achievement, self-realization and social support. These results are mostly consistent with the theories of goal achievement, Deci and Maslow. In the course of the study, differences in awareness of motives by the group of initial sportsmanship and the group of sports perfection were revealed (table 1).

Table 1. The difference in awareness of the significant motives for sports activity in the groups of sports perfection and the initial sports skill

\begin{tabular}{|c|c|}
\hline Group of sports perfection & Group of initial sportsmanship \\
\hline 1. I especially like this sport $-73 \%$ & 1. I especially like this sport $-52 \%$ \\
\hline $\begin{array}{l}\text { 2. I would like to achieve my goal (important } \\
\text { and meaningful for me) }-90 \%\end{array}$ & $\begin{array}{l}\text { 2. I would like to achieve my goal (important and } \\
\text { meaningful for me) - } 64 \%\end{array}$ \\
\hline 3. I strive for self-fulfillment - $90 \%$ & 3. I strive for self-fulfillment - $56 \%$ \\
\hline 4. I want to show good results $-100 \%$ & 4. I want to show good results $-80 \%$ \\
\hline $\begin{array}{l}\text { 5. I like to perform the tasks set by my coach - } \\
70 \%\end{array}$ & $\begin{array}{l}\text { 5. I like to perform the tasks set by my coach - } \\
56 \%\end{array}$ \\
\hline $\begin{array}{l}\text { 6. There are good relationships among the } \\
\text { athletes in my team }-70 \%\end{array}$ & $\begin{array}{l}\text { 6. There are good relationships among the } \\
\text { athletes in my team }-40 \%\end{array}$ \\
\hline
\end{tabular}

As can be seen from the Table 1, motivation which is important for athletes of sports perfection group is not the same for most of athletes from the initial sportsmanship group. Trainers need to take this fact into account and create conditions for the development of motivation inherent in athletes of sport improvement group right from the initial training stage.

At the third stage of the study, the motivation of professional athletes was studied. In the course of the study, a standardized interview method was used, as well as an inductive and deductive method for analyzing the responses of elite athletes.

It was revealed that elite sportsmen did not imagine themselves as champions and did not think about benefits that sports could provide them when they entered the sport without motivation for self-realization. Instead, the main and decisive motivations for going in for sports were broad social motives: "to be among my peers", "to participate in competitions", "to travel to other cities, to participate at the training camps". The leading reasons for entering sports at the initial stage were: to become the best runner at school, to be a leader among peers. At the same time, all athletes mentioned joy and pleasure of practice and importance of these emotions in overcoming the difficulties and failures in the competitions.

Among the factors influencing the motivation of sports activities, professional athletes noted both objective and subjective difficulties. So, athletes indicate that in the period of transition from the stage of sports perfection to the level of professional sports, they did not have a clear understanding of tactical and strategic tasks, or algorithm for achieving high sports results. One of the reasons for this is that the planning process was fully responsibility of the trainer and the athletes themselves were almost not included in the planning process of their own activity. This fact was noted by 
athletes as one of the reasons for the decrease in their motivation, which caused problems with proper performance of training work, and this may lead to injuries.

In our research six professionals mentioned injuries as a factor of greater awareness on the physical condition and ability to cope with injuries, which seems to be very important competence for the further successful sports career.

After the injuries the attitude to sports changes in terms of more interest to the issues such as: means of rehabilitation, methods of training, achievements of pharmacology, self-discipline, selforganization and responsibility, as well as psychology of competition. Eight athletes showed their desire to meet specialists and discuss achievements in sports in a broader context.

As soon as one realizes that sports achievements are possible only on the base of conscious planning of the sports activity and sports regime, there will be rethinking of the goals of the sports activity and the desire to concentrate on the main goal appeared.

\section{Summary}

Professional athletes specify motives for self-actualization, self-recognition, success orientation, achieving "one's own" goal as most important ones. At the same time, all athletes note that financial reward in sports can not serve as a main motivation and main goal of sports activity.

Thus, the interview with professional athletes makes it possible to conclude that the change in motivation for athletics takes place during a sports career. At the initial stage of sports mastery broad social motives such as pleasure from the athletics activity takes place, then at the stage of sports perfection injuries are possible and motivation turns into willingness to overcome the difficulties of sports, replaced by the motive of self-realization.

The results of the study allow us to draw conclusions on the motives, which athletes in athletics (runners for short, medium and long distances) prefer and which are related to the growth of sportsmanship throughout the sports career.

At the stage of initial sportsmanship, the goals of most athletes are not long-term, they are not related to future victories at the European and World Championships, so the most preferable are wishes of athletes to improve their athletic performance, willingness to make efforts to develop their abilities and desire to enjoy training and competition with peers. At the stage of sporting perfection the significance of the sporting result is increased, new goals are realized, therefore the motivation for achieving the highest results and setting the records at the championships of Russia or Europe is the most pronounced among the athletes. At the same time this motivation can lead to extra efforts of athletes and may cause injuries, so achievement motivation as well as selfdevelopment goals set in cooperation with the coach, psychologists, nutritionists and other specialists are preferable. The team should create a favorable atmosphere for everyone, it would ensure the need of athletes in social support and significant relationships.

At the stage of achieving higher sportsmanship, when athletes participate in World and European championships, as well as at the Olympic Games, athletes should be prepared for socially responsible behavior, performing in front of spectators, fans, judges etc. This will be promoted to a greater extent by motivation for self-realization and achievement of professional skills, rather than material or personally prestigious motivation.

Further studies should be aimed at justifying the factors and conditions that contribute to the formation of long-term motives for athletics.

\section{References}

[1] N.B. Stanbulova, Psychology of sports career. Saint Petersburg, Career Center, 1999. (in Russian)

[2] C. Harwood, C.M. Spray, R. Keegal, Achievement goal theories in sport. In T.S. Horn (Ed.), Advances in sport psychology, third ed., Human Kinetics, Champaign, IL, 2008, 3, pp. 157-185. 
[3] E.L. Deci, R.M. Ryan, Self-determination theory and the facilitation of intrinsic motivation, social development and well-being [J]. American Psychologist, 2000, 55 (1) 68-78.

[4] Abraham H. Maslow, Motivation and Personality, second ed., Harper \& Row, New York, 1970.

[5] B. Weiner, An attributional theory of achievement and emotion [J]. Psychological Review, 1985, vol. 92, (4) 548-573.

[6] V. Malkin, L. Rogaleva, System of psychological work in sport [J]. International Journal of Psychology, 51 (S1), 1114.

[7] D. Teipel, R. Kemper, Specific Motivational Aspects in Female Soccer Referees, Halkidiki, Greece, Book of abstract, 2007, 362.

[8] V. Kim, A. Kim. Ski and Injury, Giga Trade, Almaty, 2010. 